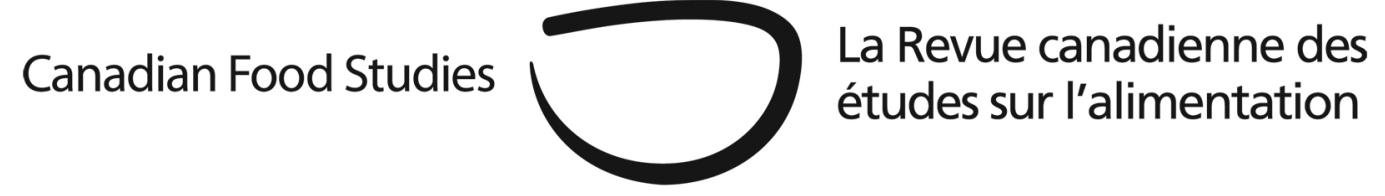

\title{
Audio-Visual Work
}

\section{Voir le jour: Breastfeeding and the commons}

\author{
Natalie Doonan* \\ Institute for the Public Life of Arts and Ideas, McGill University
}

\begin{abstract}
This research-creation project focuses on breastfeeding in public as an act of claiming space for the common good. Its audio-visual component, "Voir le jour," is part of a larger work that includes community screenings and locative storytelling. "Voir le jour" consists of recordings of nursing mothers, breastfeeding experts, and activists sharing their stories about the joys and challenges of breastfeeding outside the home. These stories are accompanied by a slideshow of photographs depicting moms nursing in public spaces. "Voir le jour" renders the labour of mothering audible and visible in public spaces, including online. It was created in part for use by the breastfeeding support organization Nourri-Source Montréal. "Voir le jour" contests the notion that "public" and "private" are distinct spatial categories. The fact that breastfeeding is commonly relegated to the sphere of domestic activity is a testament to the tenacious grip of patriarchy in everyday life, and leads to isolation for many new mothers. The discomfort that may be felt in response to seeing intimate experiences between mothers and babies is part of transforming the myth that private and public activities and spaces are discrete and separate spheres.
\end{abstract}

Keywords: performance and mothering; breastfeeding and public space; intimate citizenship; new maternalisms; mothering and public space; affective labour; common good 
I am a multimedia and performance artist, researcher, writer, educator and mother. My work focuses on making things public, and centers on the connections between taste and place. "Voir le jour” is an audio-visual work that presents breastfeeding as an act of claiming space for the common good. I use the term "common good" to mean that the pursuit of individual happiness is connected to the well-being of all members of society. ${ }^{1}$ Bringing breastfeeding into the light of day and accommodating nursing mothers outside the home has the added advantage of making public spaces more inclusive for everyone. While capitalist and patriarchal economies are driven by the goal of individual profit, common goods are those resources that are of benefit to all members of a community. ${ }^{2}$

The audio-visual component of "Voir le jour" is based on recordings from interviews that I conducted with nursing moms, breastfeeding experts, and activists who shared their stories about breastfeeding in public. These stories are accompanied by a slideshow depicting moms nursing in public spaces. Through community screenings and online publication, "Voir le jour" renders the labour of mothering audible and visible in public spaces. ${ }^{3}$ It contests the notion that "public" and "private” are distinct spatial categories. ${ }^{4}$ The fact that breastfeeding is commonly

\footnotetext{
${ }^{1}$ The point of the commons from my perspective is to create a shared space in which varied needs and interests can be expressed and served. Like Nancy Fraser, I believe that "a plurality of competing publics better promote the ideal of participatory parity than does a single, comprehensive, overarching public" (Habermas and the Public Sphere 122). Furthermore, participation in the commons can and should be expressed in non-verbal ways too. The video "Voir le jour" communicates affectively the experiences of mothers not only through their words, but also through tone of voice, laughter, hesitations and imagery.

${ }^{2}$ Breastmilk is ideally formulated to provide all of the nutrition that human babies require for their first six months of life. Furthermore, it is usually free - one of the rare foods that do not have to be purchased. As such, breastfeeding is the primary form of food sovereignty because it is produced independently, it is nutritionally and culturally appropriate, and it is ecologically and economically sustainable. Breastfeeding is thus a common good in the sense that it offers the ideal foundational food on which to raise future generations. More than this, creating public spaces that support breastfeeding benefits everyone in society because it promotes gender parity by recognizing maternal labour. Not to mention the fact that making spaces conducive to breastfeeding also makes them accessible to a wider range of people, such as those using wheelchairs or needing extra space to sit and move around.
}

3 “Voir le jour” is part of a larger volunteer project that I am working on for the breastfeeding support organization Nourri-Source Montréal to help promote their web and mobile phone application La Route du Lait. This tool displays a map of the city that indicates participating businesses where nursing mothers are welcomed and provided a place to sit and breastfeed without having to make a purchase. Twenty participants have contributed photos and stories to the project, which I have used to create the audio-visual work published here. I have also culled photos from Flickr's Creative Commons archive online. "Voir le jour" is being screened at events, the first of which was the launch of La Route du Lait, where it was projected in the front window of Senthé : Salon de Thé in Montréal (one of the participating businesses in La Route du Lait). The next part of this project will involve uploading the stories that I have recorded as .mp3 files directly onto La Route du Lait.

${ }^{4}$ A rich feminist scholarship theorizes and challenges the hierarchies and binaries that structure society and thought. See for example Pratt and Rosner (2012), who write that: "Intimacy suggests something hidden away from the larger world, apparent only to the one or few on the inside. It refers to that which is walled off from the public sphere, from governance and regulation, from oversight. Intimacy has been traditionally associated with the feminine-and, not coincidentally, has sometimes been sidelined in scholarly inquiries. Feminist approaches to the intimate have sought to redress this exclusion and have distinguished within the sphere of intimacy a number of rubrics, prominently including feeling and affect; attachments to friends, families, and lovers; and the personal. Looking more closely at 
relegated to the sphere of domestic activity is a testament to the tenacious grip of patriarchy in everyday life, and leads to isolation for many new mothers. The discomfort that may be instigated by seeing intimate experiences between mothers and babies is part of transforming the myth that private and public activities and spaces are discrete and separate spheres. ${ }^{5}$

Why is this important? Infant formula offers mothers and families an important option and can even save lives. It should thus be supported as a choice. However, in many cases, women who are physically capable of breastfeeding lack the social support to make it equally available as an option. One Canadian study shows that only $13.8 \%$ of mothers continue to breastfeed exclusively for the first six months of life, as recommended by the World Health Organization, Health Canada, the Public Health Agency of Canada, the Canadian Paediatric Society and others (Al-Sahab et al, 2010). Its authors write that: "Risk factors for early breastfeeding termination were [also] found to be associated with early hospital discharge, minimal breastfeeding support and receiving advice on formula feeding." Women who decide to breastfeed do so within a dominant culture that favours formula feeding. ${ }^{6}$ Common barriers to breastfeeding include low income, belonging to an ethnic minority, youth, and full-time employment (Dennis, 2002). Studies show that these challenges can more likely be overcome with the help of social support networks. ${ }^{7}$ It is particularly important to point out that access to education and economic resources significantly increase the likelihood of breastfeeding, meaning that promoting breastfeeding as a choice for mothers is a matter of social justice. ${ }^{8}$ What I mean by this is that taking breastfeeding seriously for the common good entails making social benefits such as education, paid maternity leave, and on-site childcare and nursing/pumping rooms in the

the development of this work can help us to see the diverse ways in which the discourse of intimacy can be connected to that of the global” (4-5).

${ }^{5}$ In the field of visual and performance art, public/private binaries have been contested by artists such as Mierle Ukeles Laderman, who in the 1970s brought feminized domestic activities such as cleaning and childcare into the rarefied public space of museums. Ukeles' practice has evolved to include ongoing work as artist-in-residence at New York City’s Department of Sanitation, where she brings devalued and obscured social labour into public view. Furthermore, recent exhibitions such as "New Maternalisms Redux," curated by Natalie S. Loveless (the third in the "New Maternalisms" series) and "The Let Down Reflex," curated by Amber Berson and Juliana Driever have worked to make spaces for parenting within art worlds, posing a further challenge to the segregation of domestic and common spaces.

${ }^{6}$ This article argues that even studies that show negative effects of formula feeding misleadingly imply that breastfeeding poses health risks: "Health Professional Knowledge of Breastfeeding: Are the Health Risks of Infant Formula Feeding Accurately Conveyed by the Titles and Abstracts of Journal Articles?” by Smith, Dunstone, Elliott-Rudder, 2009. http://journals.sagepub.com/doi/abs/10.1177/0890334409331506

${ }^{7}$ See “The experience of nursing women with breastfeeding support: a qualitative inquiry” by Chaput, Adair, NettelAguirre, Musto, Tough, 2015. http://cmajopen.ca/content/3/3/E305.abstract

${ }^{8}$ For more on the demographic, physical, social and psychological variables at play in continuance of breastfeeding see "Variables Associated With Breastfeeding Duration” by Diane Thulier and Judith Mercer, 2009. http://onlinelibrary.wiley.com/doi/10.1111/j.1552-6909.2009.01021.x/full and "Breast-feeding initiation in lowincome women: Role of attitudes, support, and perceived control,” by Khoury, Moazzem, Jarjoura, Carothers and Hinton, 2005. http://www.whijournal.com/article/S1049-3867(04)00116-1/abstract?cc=y= 
workplace equally available to all parents. This public infrastructure is essential to sustaining breastfeeding throughout the duration that is widely recommended (two years and beyond). Changing perception of breastfeeding as a private and solitary act is not only a way to endorse it as a choice, but also promotes a more inclusive notion of public space. Social scientist Lisa Smyth (2009) argues that: "Breastfeeding offers a useful example through which to consider the extent sexualized bodies, generally regarded as aspects of 'private' life, can and cannot inhabit and participate in the 'public' world...” (p. 123). It has been argued that breastfeeding in public can be troubling for some because it poses a threat to the fetishization of women's bodies. Khoday and Srinivasan (2013) argue that: "breastfeeding challenges the dominant view of breasts as primarily sexual objects, and by extension the sexualized view of women as well” (p. 156). From this perspective, nursing in public contests the dominant depiction of women as sexual objects. Nursing in public does not de-sexualize mothers, but rather disrupts objectifying views of what constitutes sexuality. To understand breastfeeding as a sexual act and to perform it openly in public is to uproot a deeply held conception of sexuality as shameful and to be hidden away. ${ }^{9}$ Breastfeeding is an empowering act because it wrests authority away from binary patriarchal social structures that would place women as either good (modest, prudish, virgin) mothers or as objects for sexual consumption-and both of these roles rest on the dictate that particular acts be performed within their circumscribed spaces.

However, social scientist Rebecca Lane (2014) asks whether nursing a baby in public is really transformative if it merely involves the creation of a private bubble that does not challenge or interrupt the normal functioning of a space. It is worth noting that even the mothers who express liberal attitudes in my interviews also advocate the importance of modesty. Lane argues that women learn how to accommodate breastfeeding to normative strictures of behaviour in public space and injunctions of "good motherhood". This is a form of self-policing that emphasizes the separation of sexuality and nourishing, ultimately reinforcing, rather than challenging dominant constructions of public space.

If patriarchal and capitalist spaces are those in which stereotypes of femininity and masculinity are imposed and participation is reduced to financial exchanges, then feminist notions of public space encourage interdependence and accommodation of all bodies. ${ }^{10}$ Social

\footnotetext{
${ }^{9}$ See "Sex In Public" by Berlant and Warner, who argue that heteronormative sexuality is pervasive in everyday life, structuring socio-economic relations, as well as American dreams and aspirations-constraining the imagination of possible worlds at every turn. The implication for public life is that our sphere of action and indeed of being is defined through the narrow paradigms of citizen and consumer. Both of these rest on a false assumption of discrete, private, individual subjectivity. Berlant and Warner argue for the radical world-building and transforming potential of queer culture in assembling publics that defy belonging on the basis of privacy, patriarchy or capital (1998). Artist Vito Acconci, in his article "Public Space In a Private Time," similarly contaminates pervasive capitalist and patriarchal designs for public space through intimacy. The ideas advocated in this article are made manifest in his 1972 performance "Seedbed," in which he interrupts social propriety and spatial design by masturbating under the floorboards of a gallery while visitors stroll above.

${ }^{10}$ In the film, The Examined Life (Taylor, 2008), Judith Butler and Sunaura Taylor converse while walking. Butler suggests that: "Perhaps we have a false idea that the able-bodied person is somehow radically self-sufficient.”. A few minutes into her response, Taylor, who uses a wheelchair, says: "In a way it's a political protest for me to go in and order a coffee and demand help, simply because in my opinion help is something that we all need. And it's
} 
theorist Judith Butler (2011) writes that: "Human action depends upon all sorts of supports_it is always supported action. But in the case of public assemblies, we see quite clearly not only that there is a struggle over what will be public space, but a struggle as well over those basic ways in which we are, as bodies, supported in the world — a struggle against disenfranchisement, effacement, and abandonment". When a mother is told that: "this is not the right place to feed your baby," a line is being drawn between a territory of private consumption and the place of free communal exchange. Moments when nursing mothers are told to move along expose the fact that "public space" is not a given, but a zone of struggle. How can we create more spaces in which nursing moms feel welcomed, rather than shamed, disenfranchised, abandoned and effaced?

Brenda Dobson and Maureen Murtaugh (2001) note that: "The decline in breastfeeding 20-30 years ago has resulted in a loss of traditional knowledge and support; today's grandmothers often have no firsthand breastfeeding experience.” What can be done to reinstate this intergenerational knowledge? Any gesture that supports breastfeeding in public acts toward building the commons - a space of shared resources in which our interdependence is made manifest. Public support for breastfeeding brings more mothers into public space to feed their babies. As the mothers in my interviews express, this includes everything from making changing tables available in washrooms, to offering a smile of encouragement to a nursing mom, or handing her a glass of water. These gestures count as what Susana Torre (2000) calls “... social action that can make the environment come alive or change its meaning” (p. 145). Breastfeeding outside the home is a public display of intimacy between mother and baby-a moment in which the mother's affective labour, an unremunerated labour that lies outside of or in excess of capitalist culture-is made public. The performance of breastfeeding highlights human interdependence, thus challenging the dominant neoliberal value of self-reliance. Encouraging moms to nurse in public is thus an effort to both empower women and to promote community and equal access to common goods.

Acknowledgments: I would like to thank all of the mothers who contributed to this audio-visual work by sharing their precious time, stories, and photos. The artists who generously shared their photos of breastfeeding in public through Flickr have also significantly contributed to this work and are credited both below and in the video itself. Thank you to Virginie Paquin, Gloria Lombardi and Mathilde Gouin of Nourri-Source Montréal for helping to coordinate this project, and to the two anonymous reviewers and my sister, Christina Doonan, for their helpful feedback. Any shortcomings or oversights that remain are my own.

something that is looked down upon and not really taken care of in this society, when we all need help and are all interdependent in all sorts of ways". The commons is a space in which each person can express and receive the help or accommodation that they need. Breastfeeding bodies can also be understood as a "political protest" because they put human interdependence on view through their own vulnerability and intimacy. 


\section{Flickr Creative Commons attributions for photos in the audio-visual work}

In order of appearance:

This photo is a derivative of "DSC_7821" from the "Mothering Touch" series taken March 28, 2010 by Al van Akker, licensed under CC BY 2.0. See also www.motheringtouch.ca.

This photo is a derivative of “Pecho y lectura," taken April 2, 2008 by Daniel Lobo Daquellamanera.org, licensed under CC BY 2.0.

This photo is a derivative of "Feeding in the mall," taken February 20, 2016 by David D, licensed under CC BY 2.0.

This photo is a derivative of “056a," taken June 1, 2012 by hugabub, licensed under CC BY 2.0.

This photo is a derivative of "Breastfeeding on Capital Hill, Rotunda Steps," taken June 17, 2013 by Jacob Bøtter, licensed under CC BY 2.0. See also http://heutedenkenmorgenfertig.com/

This photo is a derivative of "DSC_7634" from the "Mothering Touch" series taken March 28, 2010 by Al van Akker, licensed under CC BY 2.0. See also www.motheringtouch.ca.

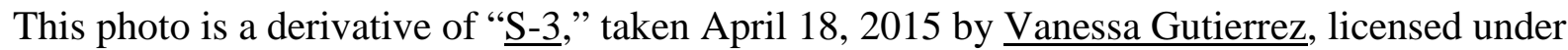
CC BY 2.0. See also http://titacgs.com.ar.

This photo is a derivative of “strike anywhere” taken May 16, 2016 by Mae Catherine Melchor, licensed under CC BY 2.0.

This photo is a derivative of "Lucy and Morgan" taken March 2002 by Martin Burns, licensed under CC BY 2.0.

This photo is a derivative of "DSC_8273" from the "Mothering Touch" series taken March 28, 2010 by Al van Akker, licensed under CC BY 2.0. See also www.motheringtouch.ca.

This photo is a derivative of “image0147: Fête du Maternage 2012,” taken September 22, 2012 by Peggy Godreuil, licensed under CC BY-NC-SA 2.0.

This photo is a derivative of "Central Park" taken May 26, 2008 by Joe Shlabotnik, licensed under CC BY 2.0. See also http://joeshlabotnik.livejournal.com/

This photo is a derivative of “the breastfeeding Lady 2" taken November 3, 2007 by Raphael Goetter licensed under CC BY 2.0. See also http://www.goetter.fr

This photo is a derivative of "DSC_ 7609" from the "Mothering Touch" series taken March 28, 2010 by Al van Akker, licensed under CC BY 2.0. See also www.motheringtouch.ca. 
This photo is a derivative of "Very young and beautiful girl having her dinner" taken September 23, 2013 by Jan Fidler, licensed under CC BY 2.0.

This photo is a derivative of "DSC_8035" from the "Mothering Touch" series taken March 28, 2010 by Al van Akker, licensed under CC BY 2.0. See also www.motheringtouch.ca.

\section{References}

Al-Sahab, B. \& Lanes, A., Feldman, M. and Tamim, H. (2010). Prevalence and predictors of 6month exclusive breastfeeding among Canadian women: A national survey. BMC Pediatrics. Retrieved from https://bmcpediatr.biomedcentral.com/articles/10.1186/1471-2431-10-20

Butler, J. (September 2011). Bodies in Alliance and the Politics of the Street. Transversal. European Institute for Progressive Cultural Politics. Retrieved from http://www.eipcp.net/transversal/1011/butler/en

Dennis, C. (January 2002). Breastfeeding Initiation and Duration: A 1990- 2000 Literature Review. Journal of Obstetric, Gynecologic \& Neonatal Nursing. Retrieved from http://onlinelibrary.wiley.com/doi/10.1111/j.1552-6909.2002.tb00019.x/full

Dobson, B. \& Murtaugh, M.A. (October 2001). Position of the American Dietetic Association: Breaking the Barriers to Breastfeeding. Journal of the Academy of Nutrition and Dietetics, American Dietetic Association, volume 101 (issue 10). Retrieved from http://www.andjrnl.org/article/S0002-8223(01)00298-X/fulltext

Khoday, A. \& Srinivasan, A. (2013). Reclaiming the Public Space: Breast-feeding Rights, Protection, and Social Attitudes. McGill JLH 147 volume 7 (issue 2), pp. 149-168.

Lane, R. (2014). Healthy discretion? Breastfeeding and the mutual maintenance of motherhood and public space. Gender, Place \& Culture, volume 21 (issue 2), pp. 195210. http://dx.doi.org/10.1080/0966369X.2013.791251.

Smyth, L. (2009). Intimate Citizenship and the Right to Care: The Case of Breastfeeding. In E. H. Oleksy (Ed.), Intimate Citizenships: Gender, Sexualities, Politics (pp. 118132). New York and Oxon: Routledge.

Taylor, A. (Director). (2008). Examined life [Motion picture]. Canada: Sphinx Productions and the National Film Board of Canada.

Torre, S. (2000). Claiming the Public Space: The Mothers of Plaza de Mayo. In J. Rendell, B. Penner and I. Borden (Eds.), Gender Space Architecture: An interdisciplinary Introduction (pp. 140-145). London and New York: Routledge. 